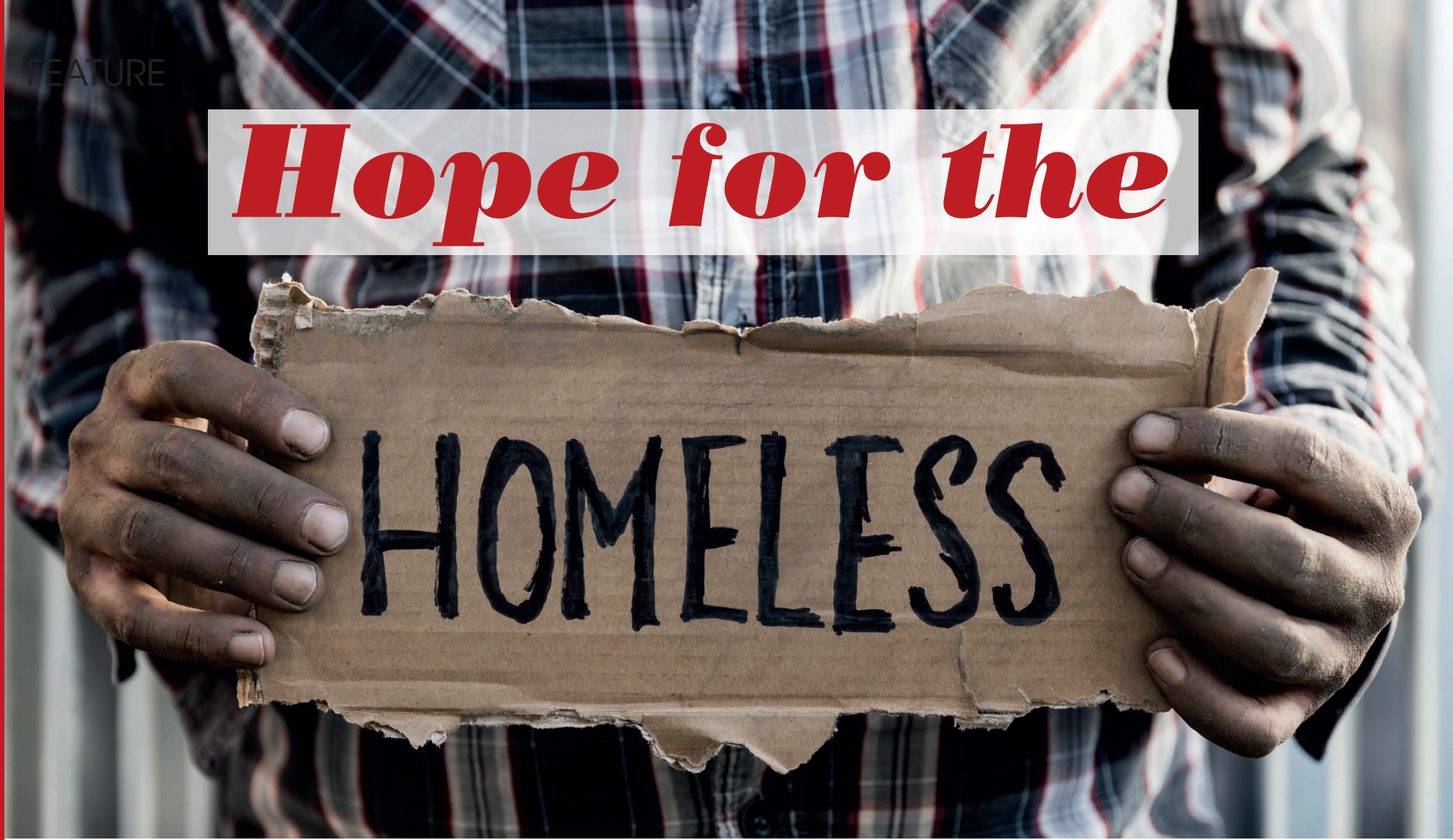

A coalition of dental professionals, dental charities and outreach organisations came together in 2018 to give voice to the work that's being done to provide dental care to the homeless and marginalised. In this special feature, three members of that coalition describe their work.

\title{
Going mobile in Manchester to meet the needs of the marginalised
}

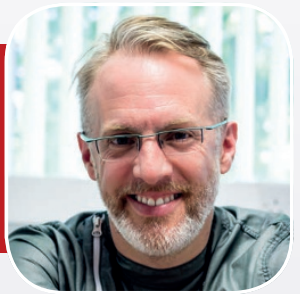

Ben Atkins describes how he and his dental team at Revive Dental Care began reaching out to patients most in need of good dentistry.

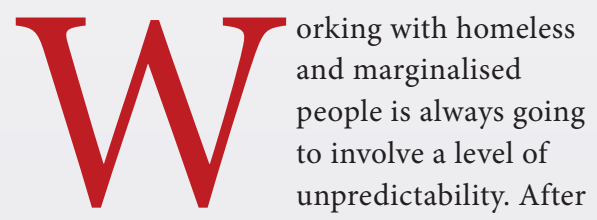
climbing a steep learning curve over nearly a decade, however, we have established systems which give us the best possible chance of building trust and delivering care to the people we wanted to reach.

\section{The background}

In 2009 Revive dental care was awarded an access contract to provide a service at the health centre in Ancoats Urban Village, Central Manchester. We reserved the first hour of treatment every evening to work with the Homeless Medical Service Unit based in the same building. If a patient attended in dental pain, then the medical reception would direct them to us. The sessions we worked were 6-8.30pm in the evening and 10-4 on a weekend or public holiday. This slot was promoted by the medical team and gradually the service was accessed by the homeless and hard to reach groups. Patients were invited to return for further treatment, but often failed to.

We encountered difficulties with the evening slots due to alcohol misuse and eventually this service became quiet due to the high failure rate. This can really affect service viability and motivation when treating patients. However, from discussions with our colleagues in the Ancoats Urban Village Medical Centre, it became obvious that there was an acute need for dental provision to support GPs in their work with the homeless.

We agreed that the patients would be better suited to a daytime clinic and we approached 
the local commissioners to fund one session per week giving access, on a drop in basis, for these patients. This service was linked to the drop in methadone clinic run by the medical practice on the same specific day each week. The collaborative working was at first successful until the methadone clinic changed their opening days. Unfortunately due to other commitments the dental clinic times were unable to change.

\section{The engagement process}

Working with a new Manchester drug service called 'RISE' and hard to reach support networks we now offer a pop up dental practice. Developing our pop-up mobile dental surgery has really engaged with the homeless patients and we understand so much more about them. For instance, after attending a drug rehabilitation day we realised that failing to access dental care could be the trigger for our clients to revert to misuse of drugs or prescribed medications.

It would appear to be far more difficult to access medical care than dental care. We found that differing levels of disease in different centres, from Dickensian decay to a patient needing a few fillings.

There are many reasons why homeless patients do not always attempt to access dental services:

\section{Confusion}

- This could be due to where and how to access care or whether they are eligible for free or subsidised care

\section{Fear of refusal or rejection}

- One of our major disappointment has been the attitude of a specific member of the Revive Team towards the homeless patients. Choosing the right team team is key when setting up a service. This gave us an insight into how patients may be treated within the general dental practice population.

\section{They have more pressing welfare needs}

- Understanding where patients are in their journey is a key factor. It might not be the dentist who can spot the patient who is ready to engage, it is a team approach.

\section{Health concerns, both mental and physical}

- Patients often take their anti-psychotic medication inappropriately and relapse into opoid use. Toothache might be the reason the patient relapses into drug use, and often is. Patients often reported a reduction in ability to eat associated with painful oral conditions.

\section{Communication issues}

- Patients can find communicating with the triage service challenging. The patients with psychological issues often found it difficult to hold a conversation for a prolonged period. For some patients this was enough to stop accessing dental services for pain relief.

\section{Chaotic lifestyle resulting in the non-} completion of courses of treatments.

- A hard to reach dental service must understand that the patients have multiple issues within their lives and dentistry might not be a priority and treatment may have to start and stop a few times. The issue of appointment attendance has been huge. Our appointment reminders (text and email) has helped.

\section{'DEVELOPING OUR POP-UP MOBILE DENTAL}

\section{SURGERY HAS REALLY ENGAGED WITH THE}

\section{HOMELESS PATIENTS AND WE UNDERSTAND}

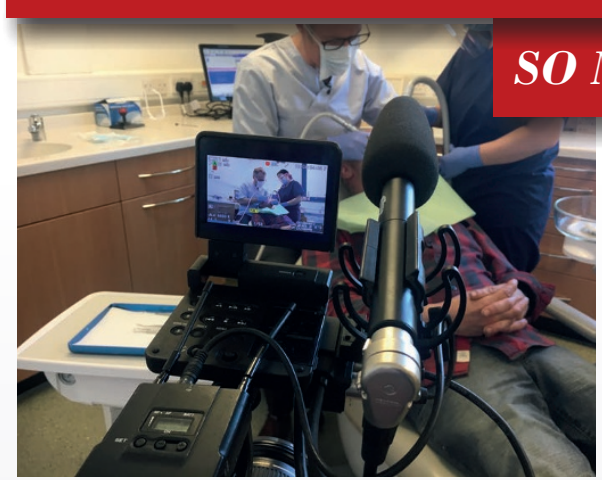

Ben and patient being filmed for the BBC

\section{The next step}

After we started the engagement programme there was an improvement in patients attending second and third appointments. We believe that this was because the dental team had gone into their world and learnt more about them. Often the patients had had a bad dental experience. If they had only been to a practice when in pain they had never really had a helpful conversation with a dentist.

A lot of the patients were in pain daily, with chronic, underlying infections and their medication often masking symptoms. Every pop up dental clinic session has approximately 10 -

18 patients and there will always be at least one patient having raging toothache. One patient had an emergency facial swelling approaching her eye which under normal circumstances would prompt a hospital referral. After a long conversation the patient allowed us to treat her provided we guaranteed that she was free to get to a meeting that afternoon.

Now our mobile unit travels to many different centres run by community groups or charities, such as the Zion Centre or the Salvation Army, sometimes every few weeks, for others every months. The service is developing and we 作

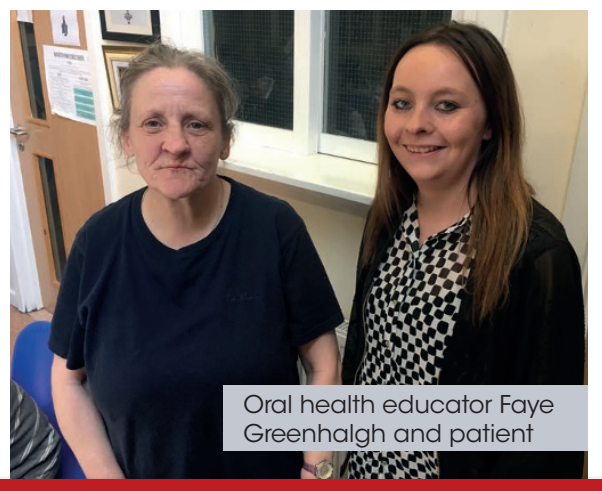

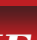

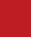

